\title{
Determination of Pullout Strength of Geogrid in Sandy Soil
}

\author{
Tushita Naidu K, Rajalakshmi R, Venkata Krishnaiah R, Dayakar P
}

\begin{abstract}
Geogrid reinforcement of soil has been successfully used for many years in a wide variety of applications. This paper presents data obtained from a series of laboratory tests performed on the geogrid. The tests were conducted to determine the mechanical property including the tensile strength of the geogrid and its corresponding pullout test. Tests were performed to find out the effect of width of geogrid on the pullout resistance. It was found that the pull-out resistance of geogrid is a function of the relative density of the soil, the length and the width of geogrid specimen. A mechanism of soil-geogrid interaction is described and used to explain the results of' the pull-out tests. A significant finding is that the selection of geogrid specimen dimensions for laboratory pullout tests must take into account the strain to failure of the soil and the stiffness of the geogrid in order to properly represent the maximum pull-out stress that will be available in field applications.
\end{abstract}

Keywords: Polymer Geogrid, Pull out resistance, Tension test, Anchorage Ratio.

\section{INTRODUCTION}

\section{A. Geogrids}

Geosynthetics are synthetic products used to stabilize terrain. They are generally polymeric products used to solve civil engineering problems. The polymeric nature of the products makes them suitable for use in the ground where high levels of durability are required. Geosynthetics are available in a wide range of forms and materials. These products have a wide range of applications and are currently used in many civil, geotechnical, transportation, geoenvironmental, hydraulic, and private development applications including roads, airfields, railroads, embankments, retaining structures, reservoirs, canals, dams, erosion control, sediment control, landfill liners, landfill covers, mining, aquaculture and agriculture.

\section{LITERATURE}

Bergado, D. T et al (1994)predicted the pullout resistance of polymer-grid reinforcement, in which they proposed that the influence of bearing member rigidity and spacing ratio (S/D) are explicitly expressed in the hyperbolic model.

Revised Manuscript Received on February 05, 2020.

* Correspondence Author

Tushita Naidu K*, B.Tech., Civil Engineering from Bharath Institute of Higher Education and Research, Chennai.

Rajalakshmi R, Bachelors, Civil Engineering from Bharath Institute of Higher Education and Research, Chennai.

Venkata Krishnaiah R, Associate Professor in Bharath Institute of Higher Education and Research.

Dayakar P, Associate Professor in Bharath Institute of Higher Education and Research.

(C) The Authors. Published by Blue Eyes Intelligence Engineering and Sciences Publication (BEIESP). This is an open access article under the CC BY-NC-ND license (http://creativecommons.org/licenses/by-nc-nd/4.0/)
They also proposed a new bearingcapacity equation for calculating the maximum pullout force. Wilson-Fahmy, R.F et al (1994) studied the anchorage behaviourby increasing use of polymeric geogrids in reinforced soil walls and steep slopes. They concluded that the presence of open structural nature of geogrids, improved the performance from other sheet-like reinforcing materials such as metallic strips and geotextiles.

Functions

Geotextiles are commonly used to improve soils over which roads, embankments, pipelines, and earth retaining structures are built. There are several types of geotextile material, including open-mesh, warp-knitted, and closed fabric or non-woven textiles. Different geotextile materials are specified for various characteristics, such as separation, filtration, drainage, reinforcement, sealing, and protection.

\section{MATERIALS}

TABLE 1

Geotechnical Properties of Sand

\begin{tabular}{|c|c|c|c|c|c|}
\hline $\begin{array}{c}\text { Specific } \\
\text { Gravity }\end{array}$ & \multicolumn{2}{|c|}{$\begin{array}{c}\text { Sieve } \\
\text { Analysis } \\
\text { Test }\end{array}$} & \multicolumn{2}{|c|}{$\begin{array}{c}\text { Compaction } \\
\text { Test }\end{array}$} & $\begin{array}{c}\text { Classification } \\
\text { of Soil }\end{array}$ \\
\hline G & $\mathrm{C}_{\mathrm{u}}$ & $\mathrm{C}_{\mathrm{c}}$ & $\Upsilon_{\mathrm{dmax}}$ & OMC & \multirow{2}{*}{ Sp } \\
\cline { 1 - 4 } 2.6 & 2.72 & 0.98 & 2.08 & 9 & \\
\cline { 1 - 3 } & - & - & $\mathrm{g} / \mathrm{cc}$ & $\%$ & \\
\hline
\end{tabular}

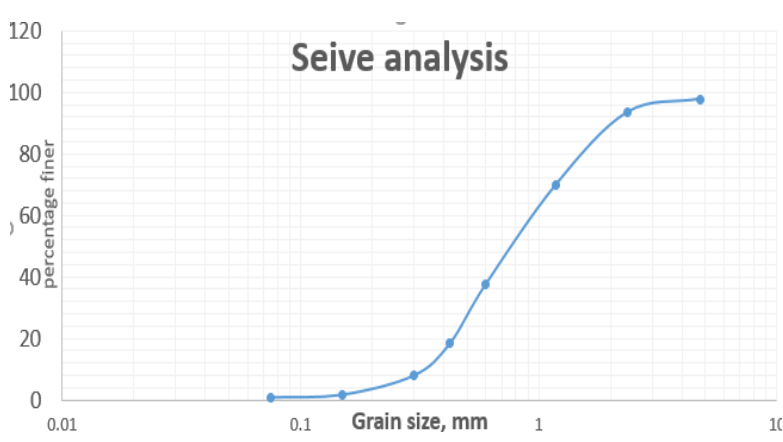

Fig.1 Grain size distribution curve of the soil sample

\section{RELATIVE DENSITY:}

The required sand sample was taken and test is performed to density of cohesion less, free-draining soils using a vibrating table. The relative density of a soil is the ratio, expressed as a percentage, of the difference between the maximum index void ratio and the field void ratio of a cohesion less, freedraining soil; to the difference between its maximum and minimum index void ratios.

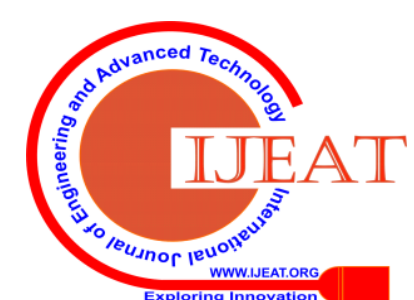




\section{Determination of Pullout Strength of Geogrid in Sandy Soil}

Relative density and percent compaction are commonly used for evaluating the state of

compactness of a given soil mass. The engineering properties, such as shear strength,compressibility, and permeability, of a given soil depend on the level of compaction.

The fibre container was filled with the sand and then placed in a vibrator. After the sand being densely compacted, it was weighed and the readings were duly noted. Their corresponding values were solved to obtain the $\mathrm{e}_{\max }$ and $\mathrm{e}_{\min .}$.

$\gamma_{\min }=\mathrm{W} / \mathrm{V}=1.74 \mathrm{~g} / \mathrm{cm}^{3}$

$\gamma_{\max }=\mathrm{W} / \mathrm{V}=2.08 \mathrm{~g}$

To find out $\mathrm{e}_{\max }$ and $\mathrm{e}_{\min }$

$\operatorname{emax}=(2.62 \times 1 / 1.74)-1=0.50$

emin $=(2.62 \times 1 / 2.08)-1=0.25$

Pullout Test onGeogridof Width 8cmLoose State (8cmWide)For Anchorage Ratio 2

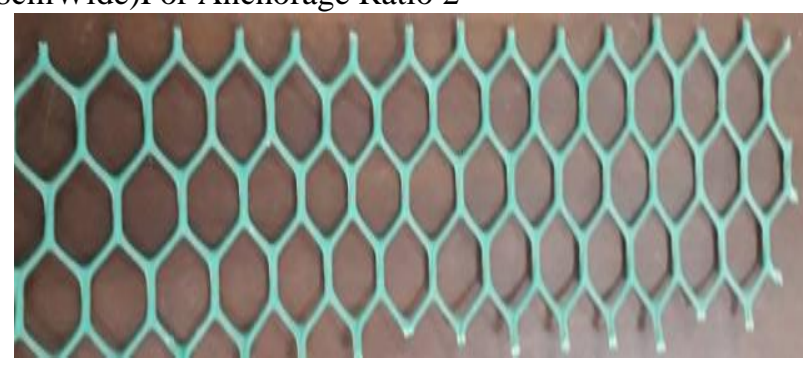

Fig.2Geogridsample

Geogrid of $8 \mathrm{~cm}$ Wide and $45 \mathrm{~cm}$ Length TENSION TEST ON GEOGRID :

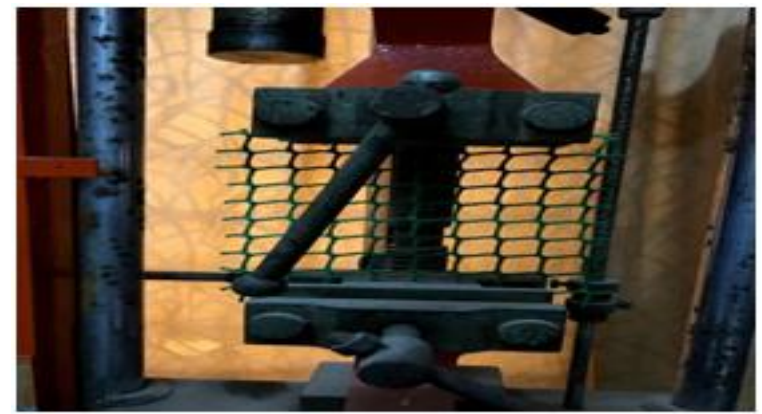

Fig. 3 Geogrid - Before Load Application

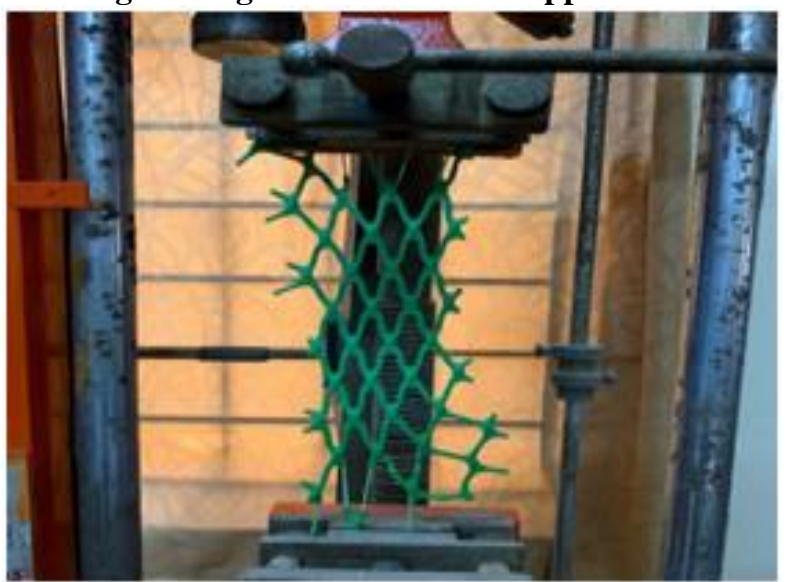

Fig. 4Geogrid at failure
TABLE II PROPERTIES OF GEOGRID

\begin{tabular}{|c|c|c|}
\hline \multicolumn{3}{|c|}{ The physical properties } \\
\hline Property & \multicolumn{2}{|c|}{ Data } \\
\hline Mesh type & \multicolumn{2}{|c|}{ Square } \\
\hline Standard color & \multicolumn{2}{|c|}{ Green } \\
\hline Polymer type & \multicolumn{2}{|c|}{ HDPE } \\
\hline Packaging & \multicolumn{2}{|c|}{ Rolls } \\
\hline \multicolumn{3}{|c|}{ Dimensional Properties } \\
\hline Property & Unit & Data \\
\hline Aperture size & $\mathrm{mm}$ & $34 * 34$ \\
\hline Mass per unit area & $\mathrm{g} / \mathrm{m}^{2}$ & 429 \\
\hline Rib thickness & $\mathrm{mm}$ & 2.8 \\
\hline Junction thickness & $\overline{\mathrm{mm}}$ & 5 \\
\hline Longitudinal rib width $l w$ & $\mathrm{~mm}$ & 3.1 \\
\hline Transverse rib width $t w$ & $\mathrm{~mm}$ & 3.1 \\
\hline Roll width & $\mathrm{m}$ & 1.2 \\
\hline Roll length & $\mathrm{m}$ & 30 \\
\hline \multicolumn{3}{|c|}{ The Mechanical Properties } \\
\hline Peak Tensile Strength & $\mathrm{kN} / \mathrm{m}$ & 1.92 \\
\hline Elastic modules & $\mathrm{GPa}$ & 0.32 \\
\hline Upper yield strength & $\mathrm{MPa}$ & בn- \\
\hline Lower yield strength & $\mathrm{MPa}$ & ב-n \\
\hline Tensile strength & $\mathrm{MPa}$ & 1 \\
\hline Fracture percentage elongation & $\%$ & -98.0 \\
\hline Percentage elongation at maximum load & $\%$ & 1.5 \\
\hline Total percentage elongation & $\%$ & 8.5 \\
\hline
\end{tabular}

The tensile strength was found to be $1.92 \mathrm{kN} / \mathrm{m}$ during its peak. The dimensional properties such as rib thickness, junction thickness, longitudinal and transverse rib width of geogrid play important role in the mechanical properties such as tensile and elastic modulus.

\section{METHODOLOGY}

A. Pullout Test

Good properties of various geogrids and geonets as well as the possibility of connecting them with other geotextiles cause that the geomaterials are widely used in road construction and civil engineering. The increasing application of geotextile materials induces a need of more careful examination of soil - reinforcement interaction mechanisms. Technical and economical effects of geotextiles (e.g. simplicity of use and lower transportation costs, respectively) are strongly related to the proper exploitation of physical and mechanical properties of the materials itself as well as the soil-reinforcement system. The appropriate determination of the value of force required for pulling out the geogrid from the soil is of the significant importance for reinforced soil structures. The effects expected are dependent on the sufficient anchoring of the reinforcing material in the soil. A source of essential information regarding the behaviour of the soilreinforcement system can be pullout tests. A standard testing procedure for determination of the geotextile-soil interaction properties has not been established until now. 


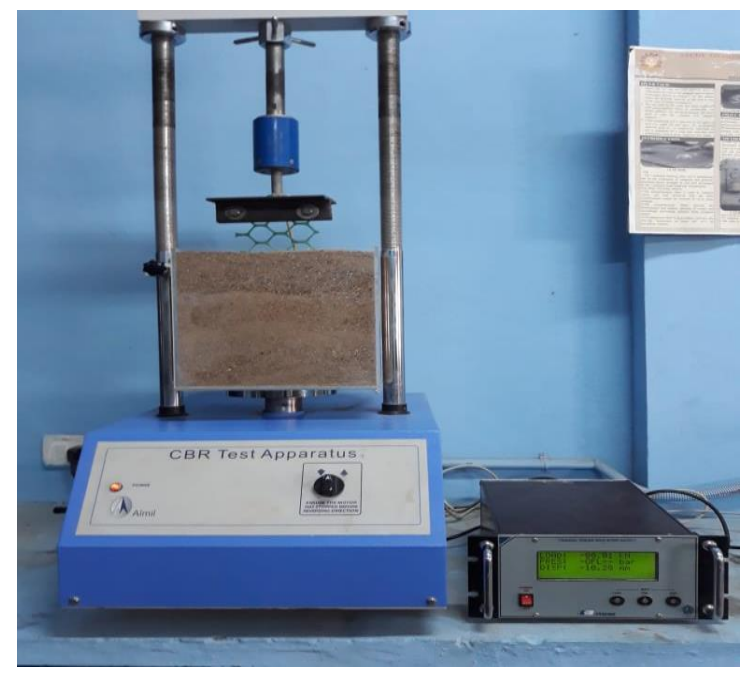

Fig. 5 Experimental setup for pullout test

\section{RESULTS AND DISCUSSIONS}

The load per unit width and the displacement relationship of the geogrid placed in the sand of varying states such as loose, medium dense and dense state was estimated comparatively along with the geogrids of different size $8 \mathrm{~cm}, 10 \mathrm{~cm}$ and $15 \mathrm{~cm}$ respectively. The results obtained is discussed below.

For 8cm Wide Geogrid

Pullout Resistance With Respect To Anchorage Ratio 2 PULLOUT RESISTANCE WTTH RESPCT TO ANCHORAGE

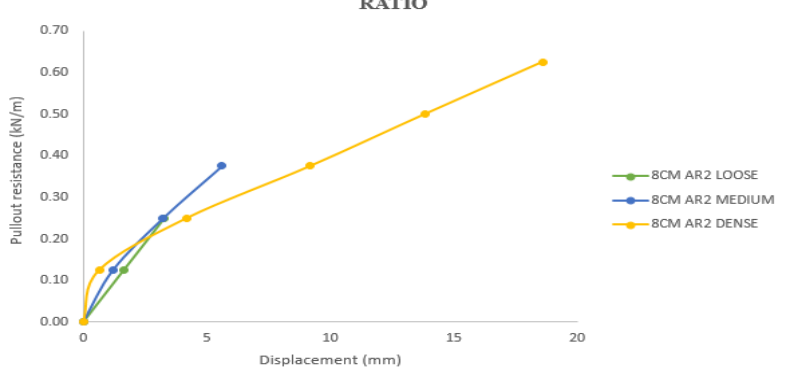

Fig. 6 Comparison with respect to various states of sand

The geogrid at medium dense state showed 52\% when the anchorage ratio is 2 . At $0.63 \mathrm{~mm}$ of displacement in the dense state, the resistance was found to be tripled.

Pullout Resistance With Respect To Anchorage Ratio 1

The resistance at medium dense state was found to be $152 \%$. With respect to dense state, the percentage increase was almost twice compared to loose and medium dese state, i.e.,200\% pullout resistance.

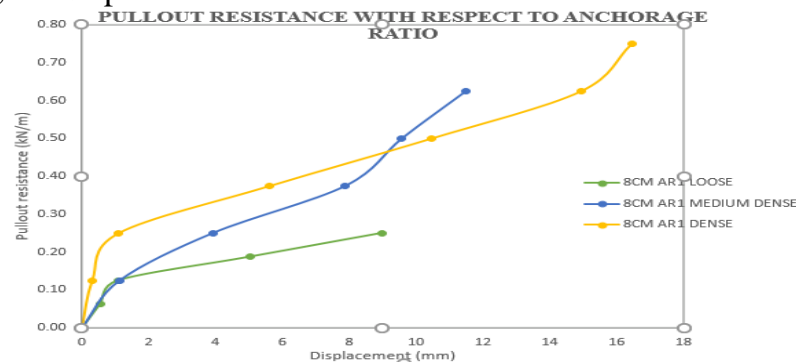

Fig. 7 Comparison with respect to various states of sand

Pullout Resistance With Respect To Anchorage Ratio 0

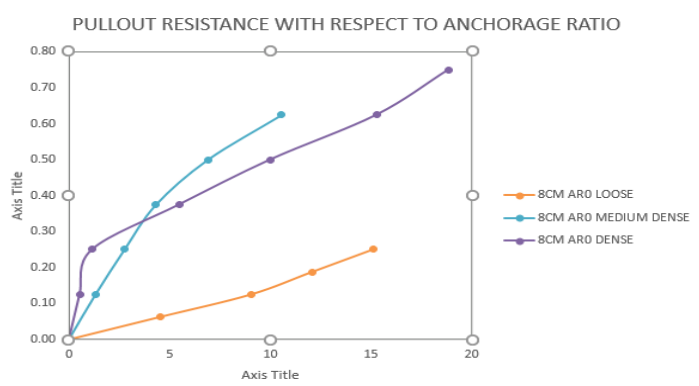

Fig. 8 Comparison with respect to various states of sand For $10 \mathrm{~cm}$ Wide Geogrid .

PulloutResistance With Respect To Anchorage Ratio 1

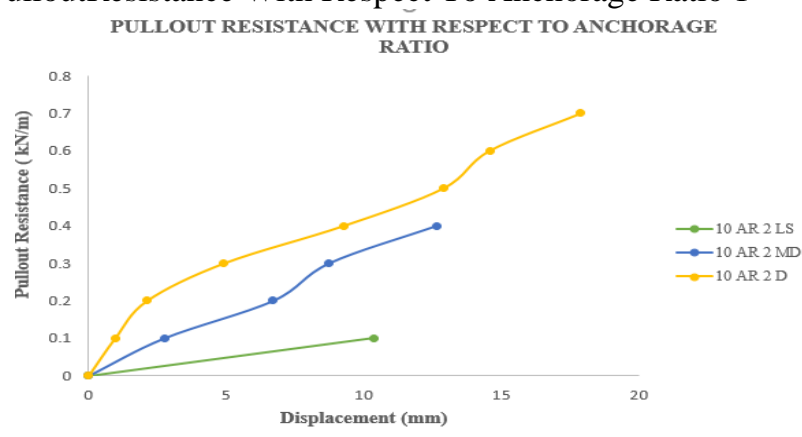

Fig. 9 Comparison with respect to various states of sand

Initially, the geogrid showed $300 \%$ at medium dense state. On calculating the pullout resistance for dense sand, the geogrid showed twice the increase in its resistance i.e., $600 \%$. So it can be said that, pullout resistance increases with respect to it corresponding variation in the state of the sand. Pullout Resistance With Respect To Anchorage Ratio 1 The pullout resistance for the medium sand from the above fig. 37 is found to be $300 \%$. Further, the resistance for the dense sand was calculated to be $500 \%$. This indicates that, on increasing the density of the soil with respect to $e_{\max }$ and $\mathrm{e}_{\min }$ values, a significant increase in the pullout resistance can be observed.

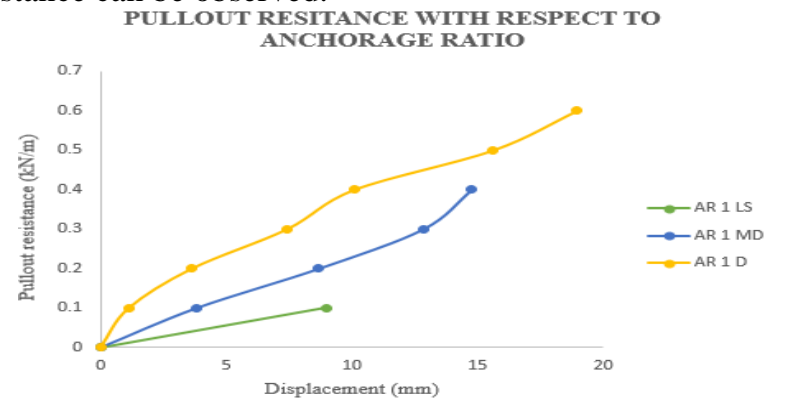

Fig.10 Comparison with respect to various states of sand

Pullout Resistance With Respect To Anchorage Ratio 0

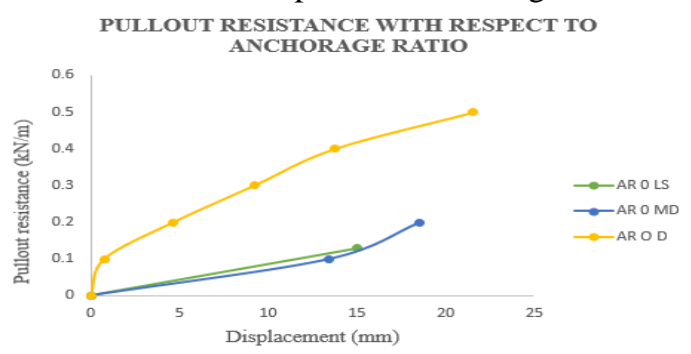

Fig. 11Comparison with respect to various states of sand For $15 \mathrm{~cm}$ Wide Geogrid

Published By:

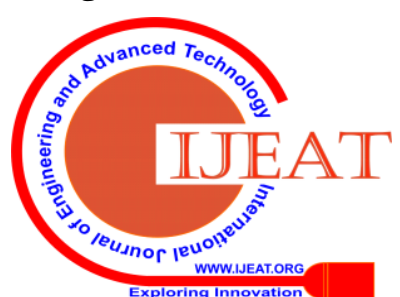


Pullout Resistance With Respect To Anchorage Ratio 2

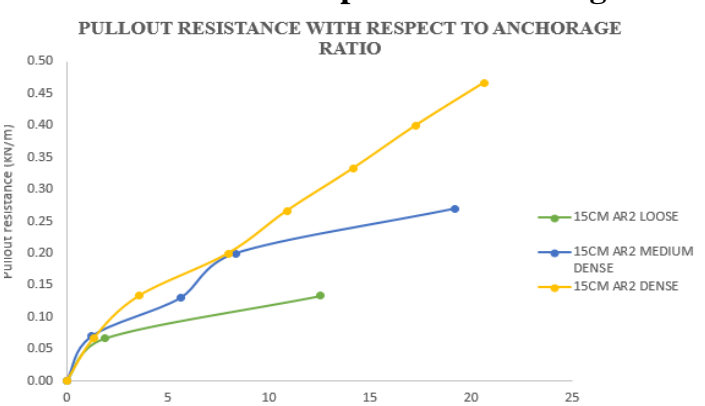

Fig. 12 Comparison with respect to various states of sand

Initially, the geogrid showed $107.6 \% \%$ at medium dense state. On calculating the pullout resistance for dense sand, the geogrid showed twice the increase in its resistance i.e.,, $261.5 \%$. So it can be said that, pullout resistance increases with respect to it corresponding variation in the state of the sand.

\section{Pullout Resistance With Respect To Anchorage Ratio 1}

The resistance at medium dense state was found to be $285.7 \%$. With respect to dense state, the percentage increase was almost twice compared to loose and medium dense state, i.e.,571.4\% pullout resistance.

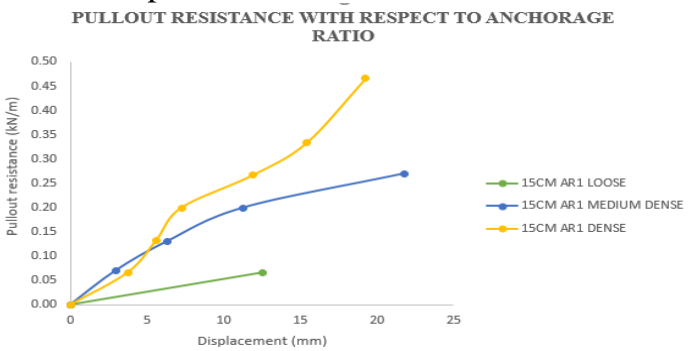

Fig. 13 Comparison with respect to various states of sand Pullout Resistance With Respect To Anchorage Ratio 0

The pullout resistance for the medium sand is found to be $285.7 \%$. Further, the resistance for the dense sand was calculated to be $571.4 \%$. This indicates that, on increasing the density of the soil with respect to emax and emin values, a significant increase in the pullout resistance can be observed.

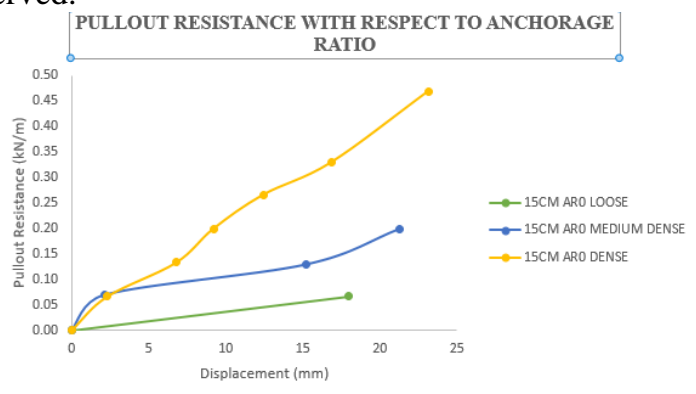

Fig.14 Comparison with respect to various states of sand Study Between same Anchorage ratio and Different Width of Geogrids

At Loose State -Anchorage ratio 2 COMPARISON BETWEEN DIFFERENT WIDTH OF GEOGRIDS

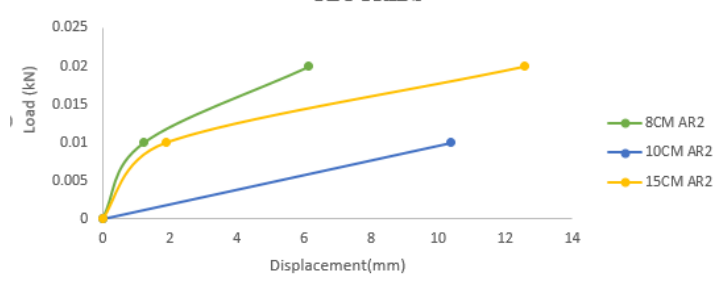

Retrieval Number: C5484029320/2020@BEIESP

\section{Fig.15 Comparison with respect to different widths of} geogrid

When geogrids of same anchorage ratio 2 and different width is taken into consideration, it can be seen that the geogrid with $15 \mathrm{~cm}$ width shows more load carrying capacity than the $8 \mathrm{~cm}$ and $10 \mathrm{~cm}$, while the $10 \mathrm{~cm}$ wide geogrid shows comparatively better results than $8 \mathrm{~cm}$. The geogrid with $15 \mathrm{~cm}$ width shows twice the increase in load carrying capacity than the $8 \mathrm{~cm}$ and $10 \mathrm{~cm}$ wide geogrid.

Anchorage Ratio 1

COMPARISON BETWEEN DIFFERENT WIDTH OF GEOGRIDS

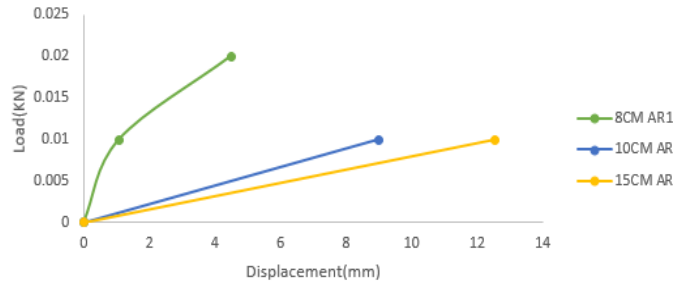

Fig.16 Comparison with respect to different widths of geogrid

On comparing the load carrying capacity of the geogrids at various widths, it can be seen that the $15 \mathrm{~cm}$ wide geogrid has more capacity to withstand the failures of the sand when compared to $8 \mathrm{~cm}$ and $10 \mathrm{~cm}$. There is a steady increase in the load carrying capacity of $15 \mathrm{~cm}$ wide geogrid which is deemed suitable for the soil reinforcements.

Anchorage Ratio 0

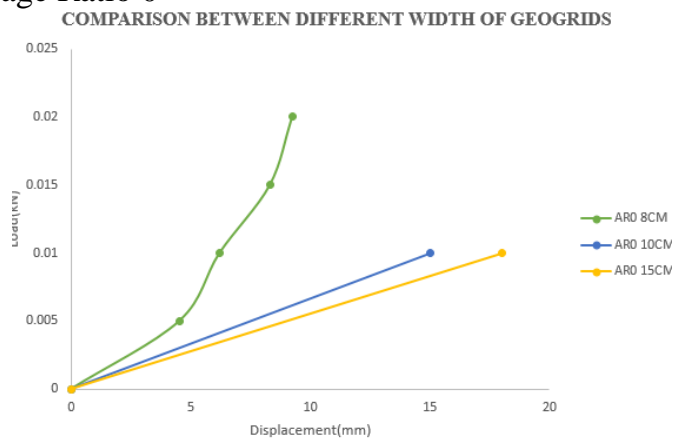

Fig. 17 Comparison with respect to different widths of geogrid

At anchorage ratio, the $8 \mathrm{~cm}$ wide geogrid shows maximum load carrying capacity at $0.02 \mathrm{kN}$ of load whereas the $10 \mathrm{~cm}$ and $15 \mathrm{~cm}$ wide geogrid shows comparatively lesser load carrying capacity.

Medium Dense State - Anchorage Ratio 2

When the sand was at medium dense state and anchorage ratio being 2, 33.3\% of loadcarrying capacity was found for

$10 \mathrm{~cm}$ wide geogrid. The load was attained at $0.04 \mathrm{kN}$ for 10 and $15 \mathrm{~cm}$ geogrid. This means that the behavioural changes of $10 \mathrm{~cm}$ and $15 \mathrm{~cm}$ does not have huge change in the load carrying capacity. Both has the capacity to carry the same load. 


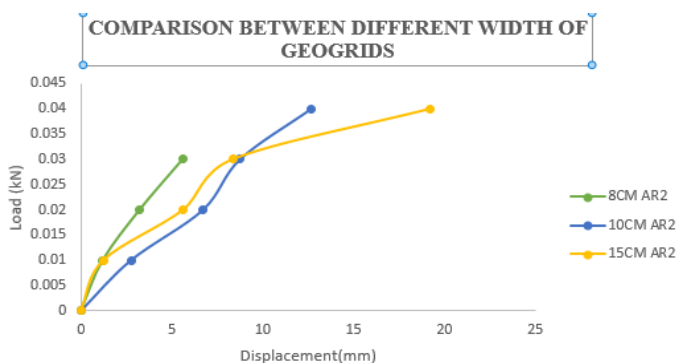

Fig.18 Comparison with respect to different widths of geogrid

Anchorage ratio 1

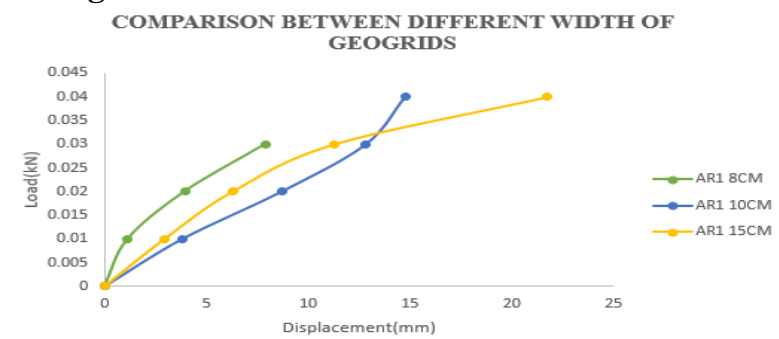

Fig.19 Comparison with respect to different widths of geogrid

Whereas, for $8 \mathrm{~cm}$ wide geogrid, the load carrying capacity is $0.03 \mathrm{kN}$. This indicates that, at AR1,

the geogrids of higher width can be used for soil reinforcement as they have high load carrying capacity.

Both $10 \mathrm{~cm}$ and $15 \mathrm{~cm}$ have the load carrying capacities of $0.04 \mathrm{kN}$ with a steady increase.

\section{Anchorage Ratio 0}

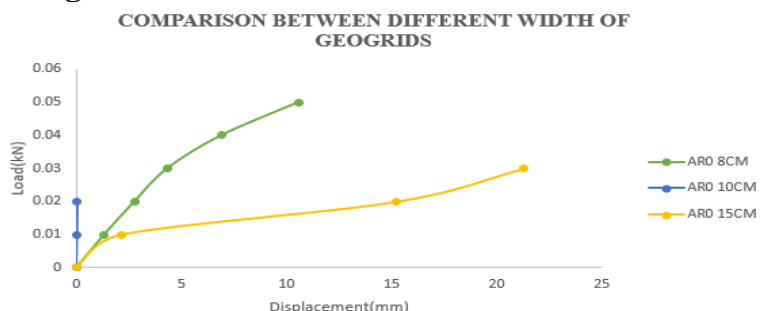

Fig.20 Comparison with respect to different widths of geogrid

When the $10 \mathrm{~cm}$ wide geogrid was placed at Anchorage ratio 0 in the soil, failure of geogrid occurred and hence it can be seen in the fig. 48 .

\section{At Dense State -Anchorage Ratio 2}

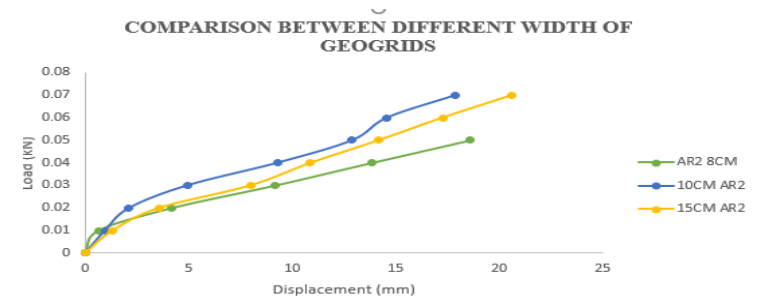

Fig.21 Comparison with respect to different widths of geogrid

At dense state, when the anchorage ratio was 2, all the 3 types of georgrids showed immense load carrying capacity meaning that, the best suitable anchorage ratio being 2 and the advisable state of sand being dense.

\section{Anchorage Ratio 1}

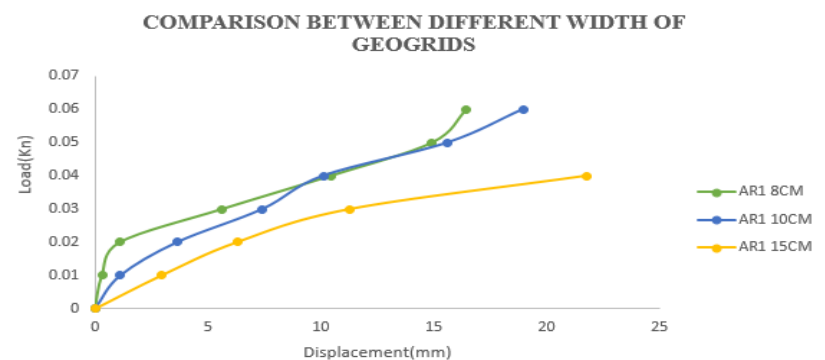

Fig. 22 Comparison with respect to different widths of geogrid

Anchorage Ratio 0

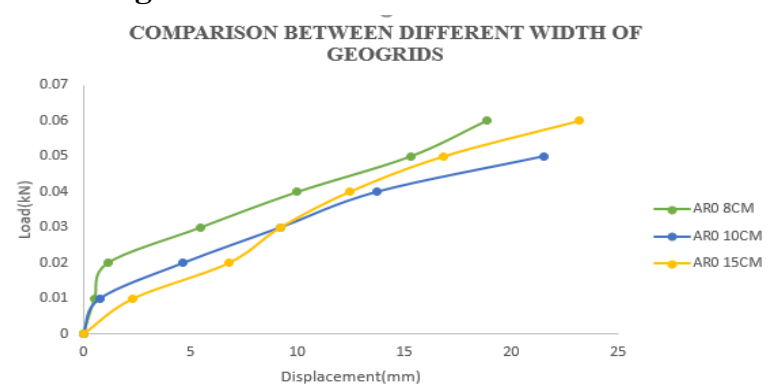

Fig. 23 Comparison with respect to different widths of geogrid

\section{CONCLUSIONS}

On performing tensile strength test on the geogrid specimen, the following conclusions maybe drawn:

1. The geogrid PMP CE 131 have tensile strength comparatively lesser than other type of geogrids. But, on large scale use of the geogrids at the construction site, it can redeemed to be useful.

2. The effect of tensile strength (stiffness) is more significant than elastic modulus when geogrids are used as reinforcement in the soil.

A soil-geogrid interaction mechanism has been described and used to explain the results of the pullout tests.

1. In the field, the embedded area of geogrid is likely to be large enough that stretching will cause the pullout stress to approach some minimum value, as demonstrated by the pullout tests reported. Thus, if laboratory tests are performed on specimens too small to include this effect, the pullout stress will be over predicted, which will lead to unsafe design. This is most likely to happen with stiff geogrid material in a dilatant soil.

2.The significance of the results of this study is that when conducting laboratory pullout tests, the relationship between the pullout resistance and displacement is to be observed and the load carrying capacity of the geogrid is to be taken into account when choosing the size of the geogrid specimen.

3.While using geogrid specimens with greater width, the load carrying capacity and the pullout resistance of the geogrid was found to be higher than general.

4.When the anchorage ratio is maximum, the resistance between the sand and the geogrid was greater at ratio 2 than anchorage ratio 1 and 0 . And hence, on providing suitable anchorage ratio to the soil, the reinforcement can be redeemed safe to avoid soil failures. 


\section{REFERENCES}

1. Bakeer, R.M., Abdel-Rahman, A,H. \& Napolitano, P. J. 1998. Geotextile friction mobilization during field pull-out test. Geotextile and Geomembranes, 16(2), 73-85.

2. Bergado, D.T. \& Chai, J.C. 1994. Pullout force-displacement relationship of extensible grid reinforcement. Geotextiles and Geomembranes, 13(5), 295-316.

3. Boyle, S.R., Gallagher, M. \& Holtz, R.D. 1996. Influence of strain rate, specimen length and confinement on measured geotextile properties. Geosynthetics International, 3(2), 205-225.

4. R.D., 1992, "Performance of a $12.6 \mathrm{~m}$ High Geotextile Wall in Seattle, Washington", Geosynthetic-Reinforced Soil Retaining Walls,Wu, J.T.H., Editor, Balkema, Proceedings of a symposium held in Denver, Colorado, USA, August 1991, pp. 81-100.

5. Kokkalis, A. and Papacharisis, N., "A Simple Dias, A.C. 2003. Numerical analyses of soil-geosynthetic interaction in pull-out tests. MSc. Thesis, University of Brasilia, Brasilia, Brazil, 115 p.

6. Wilson-Fahmy, R.F., Koerner, R.M. and Sansone, L.J. (1994). Experimental behaviour of polymeric geogrids in pullout. Journal of Geotechnical Engineering, ASCE, USA, 120(4), 661-677.

7. Sawicki, A. and Lesniewska, D. (1989). Limit analysis of cohesive slopes reinforced with geotextiles. Computers and Geotechnics, 7(1\&2), 53-66.

8. Sellmeijer, J.B. (1990). Design of geotextile reinforced unpaved roads and parking areas. Proceedings of the 4th International Conference on Geotextiles, Geomembranes and Related Products. The Hague, The Netherlands, 77-182.

9. Sellmeijer, J.B. (1990). Design of geotextile reinforced unpaved roads and parking areas. Proceedings of the 4th International Conference on Geotextiles, Geomembranes and Related Products. The Hague, The Netherlands, 177-182.

10. Zhao, A. (1996). Limit analysis of geosynthetic-reinforced slopes. Geosynthetics International, 3(6), 721-740.

11. Allen, T.M., Christopher, B.R. and Holtz, Laboratory Method To Estimate the In-soil behaviour Of Geotextiles, " Geotextitles and Geomembranes, Vol. 8, 1989, pp. 147-157.

\section{AUTHORS PROFILE}

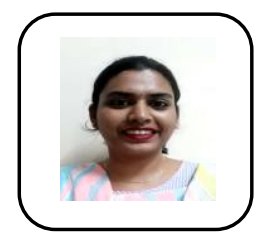

Tushita Naidu $\mathbf{K}$ received her Bachelorsin Civil Engineering from Bharath Institute of Higher Education and Research, Chennai. Her research interests predominantly lie in the field of Geotechnology and Geomechanics. Her research focuses on the geotechnical uncertainty analysis and risk assessment, slope reliability analysis, along with ground improvement techniques and associated applications in practical engineering problems.

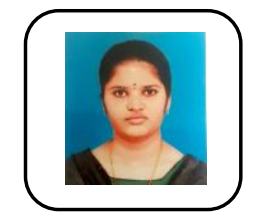

RajalakshmiR received her Bachelors in Civil Engineering from Bharath Institute of Higher Education and Research, Chennai. She is interested in the field of Geotechnology and soil - structure interaction problems.

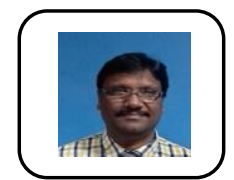

Dr.VenkataKrishnaiah Rreceived his ME in Geotechnical Engineering from MS University Baroda and Doctoral degree in Structural Engineering from Annamalai University. His specialization lies in ground improvement techniques and Geotechnology.

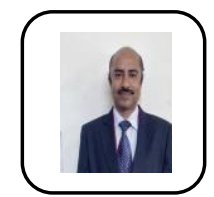

Dayakar Preceived his MS in Soil Mechanics from Anna University and currently pursuing $\mathrm{PhD}$ in Geotechnical Engineering, Bharath Institute of Higher Education and Research, Chennai. Meanwhile, He is alsoworking as an Assosciate Professor in Bharath Institute of Higher Education and Research. 